\title{
Anti-CD20 Monoclonal Antibody
}

National Cancer Institute

\section{Source}

National Cancer Institute. Anti-CD20 Monoclonal Antibody. NCI Thesaurus. Code C141215.

Any monoclonal antibody that targets CD20. 